\title{
Real-time Sound Level-Based Load Estimation in Distribution Transformer
}

\author{
Ayuba Avong Patrick, Usman Omeiza Ahmed, Bashayi Gaina James, Caleb Akezi Amlabu
}

\begin{abstract}
The technique in-used to monitor loading limits of a transformer in distribution network could impact its performance and subsequently, maintenance and service life. This research focus on optimization of performance and service life of this device when connected in distribution network. The thermal-effect technique in-used has large delay response time on loading limits monitoring. This considerably affect measurement accuracy, reliability and performance. The contributing factors which includes ambient temperature, uneven heat distribution and slow rate of thermal conductivity in transformer's metal casing. Thus, the method is inefficient for time critical monitoring of loading limits. In this paper, we proposed detecting loading limits by monitoring sound level produced from the transformer's coil. Comparatively, the proposed technique further substantiates the theory; sound propagate faster in metal than heat conductivity in the same metal. An offline data-logger device was design and developed; it was used to collect experiment data from 500KVA(33KV/415V) and 7.5MVA $(33 \mathrm{KV} / 11 \mathrm{KV})$ transformers in distribution network. The data collected were analyzed and respective results revealed 24-hours loading patterns and loading peaks. Steep raising and falling of the graph of the load waveforms indicates fast response to loading. Therefore, adopting sound-level-based loading limits monitoring will have recommended so as to improve the device performance and service life.
\end{abstract}

Keywords: real-time, sound, load estimation, distribution transformer

\section{I.INTRODUCTION}

In Electricity Distribution Networks, Distribution Transformers (DT) work by converting voltage levels and are continually connected to varying load levels for 24hrs. These devices sometime undergoing overload or they could be experiencing load unbalance among phases, most specially at peak hours. Transformer loading is therefore critical and is catalytic agents to overheating, loss of useful power and hence accelerated ageing [1]. Temperature rise in transformer is a direct function of load level and this effect influence aging of the device.

Revised Manuscript Received on July 10, 2020

*Correspondence Author

Patrick Ayuba Avong *, Department of Electrical and Electronic Engineering Technology, Federal Polytechnic Nasarawa, Nasarawa, Nigeria. E-mail: deavong12@gmail.com

Usman Omeiza Ahmed, Department of Electrical and Electronic Engineering Technology, Federal Polytechnic Nasarawa, Nasarawa, Nigeria. E-mail: eurocly@gmail.com

Bashayi James Gaina, Department of Electrical and Electronic Engineering Technology, Federal Polytechnic Nasarawa, Nasarawa, Nigeria. Email: jgainason@gmail.com

Caleb Akezi Amlabu, Department of Electrical and Electronic Engineering Technology, Federal Polytechnic Nasarawa, Nasarawa, Nigeria. Email: amlabukezi@gmail.com

(C) The Authors. Published by Blue Eyes Intelligence Engineering and Sciences Publication (BEIESP). This is an open access article under the CC BY-NC-ND license (http://creativecommons.org/licenses/by-nc-nd/4.0/)
In other to control rate of depreciation while advancing a prolong service life of any distribution transformer, sources of loss must be controlled to tolerable value. Magnetic field reversal causes loss of useful energy due to hysteresis within the core, the hysteresis loss is proportional to the frequency and is a function of the peak flux density to which it is subjected. Eddy current loss is a complex function of the square of supply frequency and inverse square of the core material thickness; this is responsible for resistive heating in the core material. Another loss that is of importance to this research is magnetostriction; the magnetic flux in a ferromagnetic material, such as the core, causes the metal to physically expand and contract slightly with each cycle of the magnetic field. This effect produces buzzing sound commonly associated with transformers, also causes loss due to frictional heating. The magnetostriction causes the alternating magnetic field forces fluctuation between the primary and secondary windings. The incited vibrations within nearby metal casing adds to the buzzing noise. The service life (Life Expectancy) in a distribution transformer is set to end when probability of failure becomes high. Also, the probability of failure becomes high when tensile strength of insulation paper has reduced by $80 \%$ of its original value. Therefore, it is critical to avoid peak loading of distribution transformers in other to enjoy long and trouble free service life.

\section{II.TECHNIQUES FOR TRANSFORMER LOAD MEASUREMENT}

Theoretical Background:

This is an experimental research aimed to investigate realtime loading response in 500KVA(33KV/415V) and 7.5MVA(33KV/11KV) transformers in distribution network. The core noise, load noise other noise effectively combined and generate audible signal that can be pick by appropriate sound sensor [3]. The audio frequencies are multiples of 100 and $120 \mathrm{~Hz}$ for $50 \mathrm{~Hz}$ and $60 \mathrm{~Hz}$ input frequencies respectively. The magnitudes of harmonics depend on the core material, core geometry, operating flux density and proximity of resonance frequencies. Sound in transformer is generated as result of electromagnetic forces interaction between load current in the windings and the leakage flux produced by this current. The frequencies in composite sound signal produced is twice the input frequency to the transformer. This sound level is proportional to load level in the transformer. The notable name-plate standard in transformer excludes printing of audio signal (dB) specification, however, other specifications are printed such as coil ratings, ambient temperature rating, load limit,

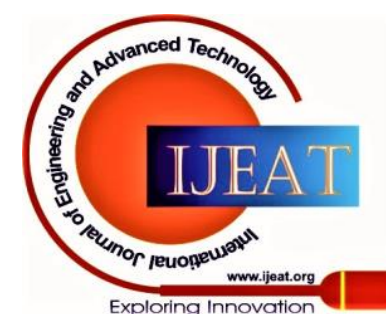


winding type on the plate. Thermal effect is a standard used to determine loading limits and the operating ambient temperature of the transformer. The temperature from coils in transformer have combined effect at a point called hotspot. Over time, hot-spot has been depending on for outdoor temperature rise in transformers' wall is the average temperature rise occurring in the coils during operation. Analysis of temperature rise allows for determining the load capacity and overloading tendencies in these transformers. In the report presented by [4] showed experimentation on thermovision method (optical detectors) to detect loading limits in distribution transformers, the result obtained has considerable accuracy well above $98 \%$ within response time of thermal conductivity on metal. The inefficiency of thermal effect was also reported in [4], therefore, measuring transformer temperature will not present a fast feedback monitoring of loading responses.

A review of IEC 600767-7, the standard loading guide for most oil-immersed transformers state that the top oil temperature inside the windings is not precisely known [5]. To be strictly accurate, the hot-spot temperature should be referred as the adjacent oil temperature which may not be the precise loading temperature due to loading.

\section{Transformer Audio Sound Response to Loading}

To improve feedback response time in load estimation, a more robust and time critical method using sound generated from the transformer is under consideration.

Transformer humming is characterized by several audio tones, with frequencies within which is audible. In addition to [3] contributions. An experiment conducted by [6] also transformer. An experimentation documented by [7], the figure 1 shows findings about core noise and loading effect in transformer. It also added, the relative magnitudes of the noise at the various harmonics depends on other factors such as material and geometry of core, its operating flux density.

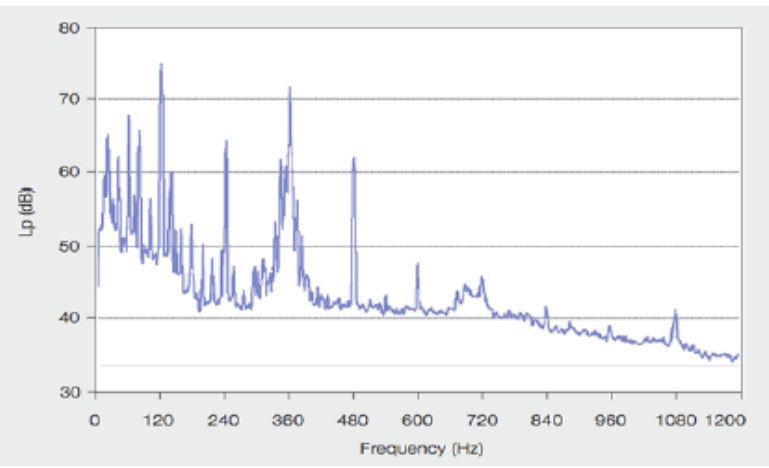

Figure 1 Frequency Spectrum of Power Transformer [1]

A report by [2] shows characterisation of no-load and load noise using Sound Pressure and Sound Intensity Methods. The sound intensity gave most accurate result, however the differences in results between the two methods have attributed to near-field reactive sound and ambient noise. will eliminate issues that bothers on size and location of hotspot of the transformer and to improve on feedback response when loading occurs.

This paper adopt technique using sound sensor to pick the frequencies within the audio frequency range $(0-16 \mathrm{KHz})$ and a Atmega328p microcontroller was dedicated for monitoring of loading limit in distribution transformer. The confirmed the three main sources of audible sound/noise in

There is need for efficient and fast response method that

sampling the output power level signal frequencies from the sound sensor. The data were stored in SD card for further analysis. The data obtained were mapped to the power ratings of the transformer and the result indicates loading levels of the transformer at different time. These same data can also be used to extract information that will reveal in further analysis the remaining service life of the transformer.

\section{III.METHODOLOGY}

There are two basic methods to measure the noise from a transformer: (i) Sound pressure method, and (ii) Sound intensity method [7]. The sound pressure method was used determine the loading pattern of transformers in distribution network. The sensor monitored the power levels of audio signal every two second for 24hours using data-logger which was placed $5 \mathrm{~cm}$ from the transformer's outside casing. Microcontroller algorithms implements data collection, data filtering and data logging. Exponential Moving Average (EMA) Low Pass Filter (LPF) and Band Pass filter (BPF) algorithms filters separates sound signal from background noise. The analysis carried out determines the loading response of the transformer. The research workflow is presented in the figure 2 .

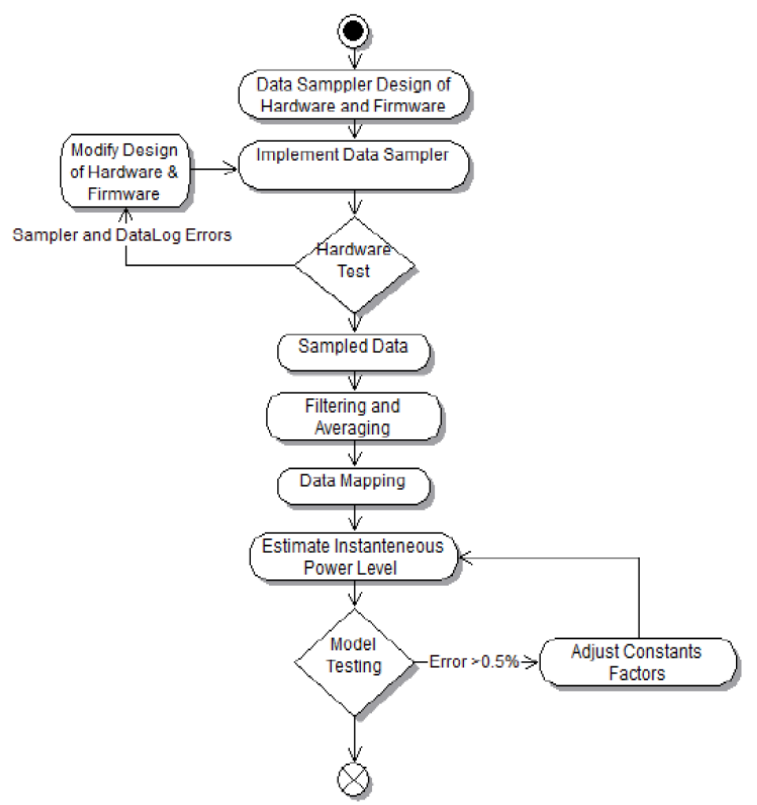

Figure 2 Research Methodology

\section{Data-logger Hardware/Firmware Design and Implementations:}

The data-logger was designed based on microcontroller Atmega328p from ATMEL. The sound sensor module designed with electric microphone, pre-amplifier (LM386), LM358 Non-inverting power amplifier. The microcontroller firmware was developed in Arduino IDE. The amplified analogue sound signal is an input to channel 0 of Analogue to Digital Converter (ADC). 1st stage pre-filtering implements averaging of 50 samples every second. The 2nd stage filtering is an EMA algorithms implemented in Low Pass and Band Pass Filters. The filtered data were tabulated and saved in SD card(2GB). The sampler takes approximately $2.184 \mathrm{~s}$ inbetween samples, the process was repeated for 24hours in

Published By:

Blue Eyes Intelligence Engineering

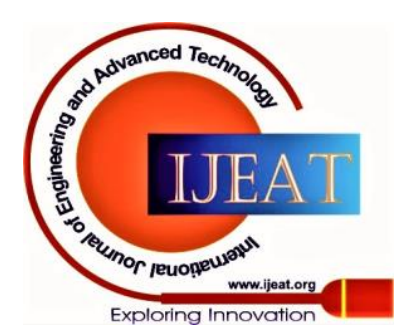


500KVA and another 24hours sampling from 7500KVA.

In each transformer 39,528 valid samples were recorded. The total time between samples.

$T_{T}=T_{D}+T_{S} \cong 2.181 \mathrm{~s}$ equ.(1)

Where $T_{T}$ is the total time in-between samples

$T_{D}$ is the delay time before next sampling

$\mathrm{T}_{\mathrm{s}}$ is the time taken in the sampling and saving in SD card.

The block diagram and implemented hardware is shown in figure 3 .

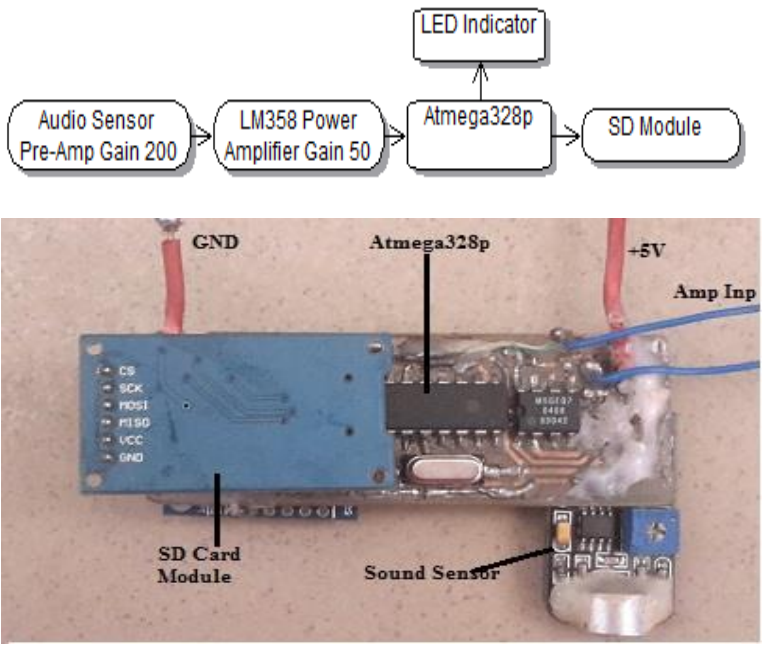

Figure 3 Data-logger

\section{Data-logger Algorithms:}

The sampling algorithm is presented in figure 4. When powered on, the system initializes the ADC channel 0 , the SD card and then delays for $4 \mathrm{~s}$ for all voltages to stabilize. Another $1000 \mathrm{~ms}$ (1s) is taken to wait before next sampling. Successful sampled data are tabulated and saved in SD card. A failed data saving operation, the data is discarded and LED indicator blinks twice with 0.5 s delay in between.

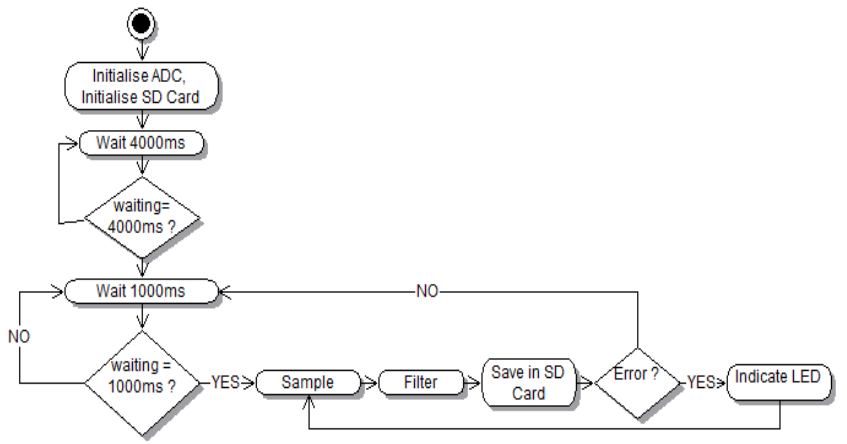

Figure 4 Sampling Algorithm

\section{The Filtering Algorithms}

Exponential Moving Average time series statistics is simple and has low memory utilization in computation. The instantaneous output is computed LPFt by taking fraction of previous output LPFt-1 and (1- LPFt-1 )*LPFt. If $a$ and $b$ are Low and High cut-off frequencies constants, then the transfer functions for Low Pass Filter (LPF) and Band Pass Filter (BPF) are given in figure 5.

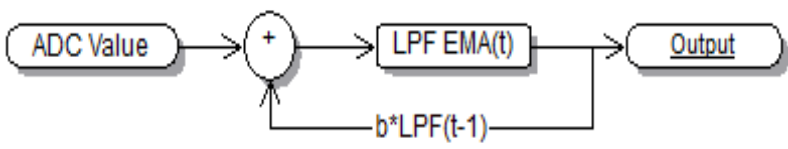

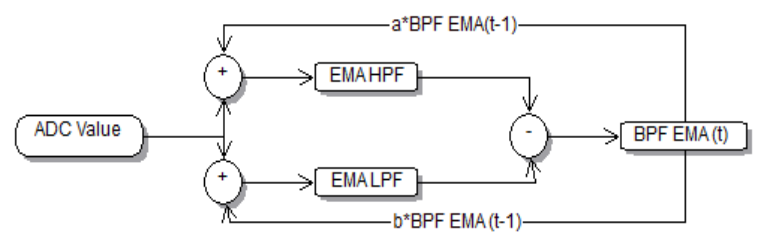

Figure 5 (a)Filter LPF and (b) BPF Transfers Functions

The Exponential Moving Average Low Pass Filter is mathematically expressed as follows.

$L P F_{E M A(t)}=a * \operatorname{ADCValue}_{(t)}+(1-a) * Y_{E M A(t-1)}$ equ. (2)

For the Exponential Moving Average Band Pass Filter

High Pass Filter

$Y_{H P F(t)}=a *$ ADCValue $_{(t)}+(1-a) * Y_{H P F(t-1)}$

Low Pass Filter;

$Y_{L P F(t)}=b *$ ADCValue $_{(t)}+(1-b) * Y_{L P F(t-1)}$ equ.(4)

Subtracting equ. 4 from equ. 3

$B P F_{E M A(t)}=Y_{H P F(t)}-Y_{L P F(t)}$

$\mathrm{LPF}_{\mathrm{EMA}(\mathrm{t})}$ is the EMA current output of Low Pass Filter BPF $_{\text {EMA(t) }}$ is the EMA current output of Band Pass Filter ADC Value $_{(\mathrm{t})}$ is the current sampled ADC value

\section{IV.RESULT AND ANALYSIS:}

The experiment was carried out on two different transformers 500KVA and 7500KVA with followings specification:

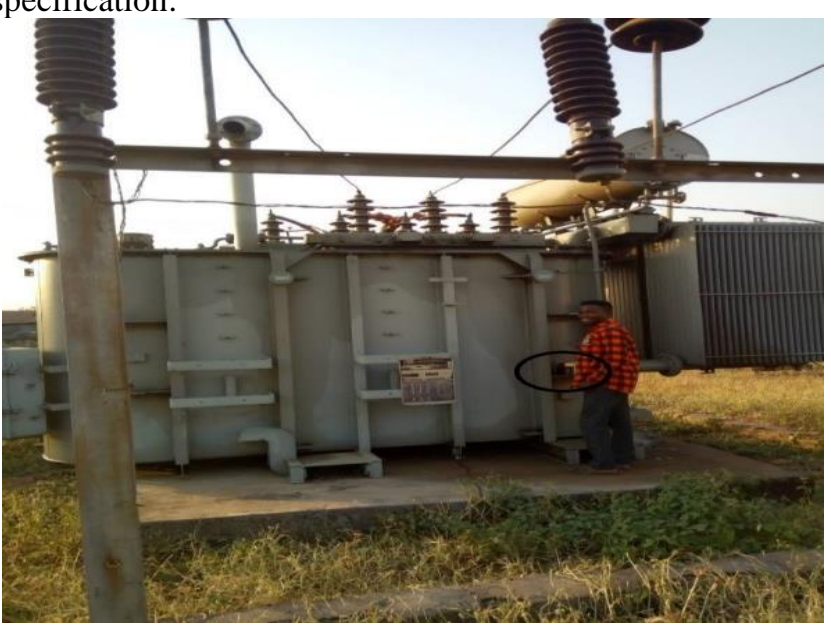

(a) Transformer rating: 7500KVA 


\section{Real-time Sound Level-Based Load Estimation in Distribution Transformer}

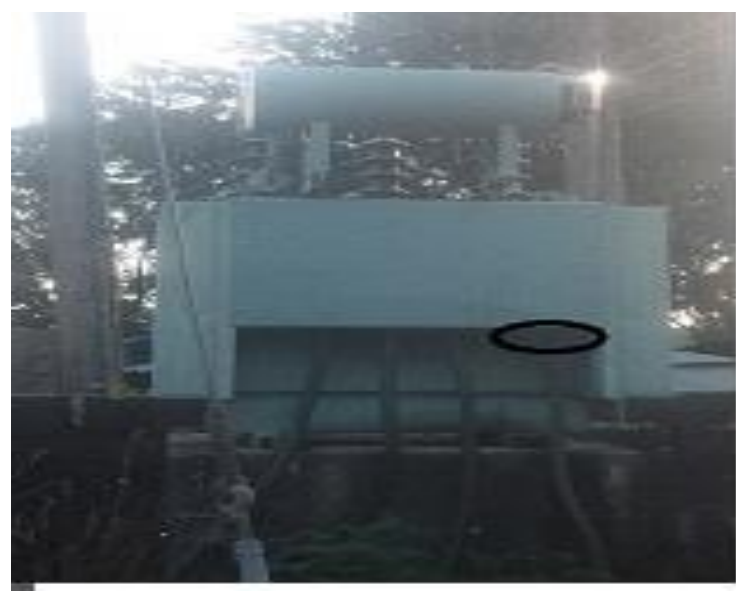

(b) Transformer rating: 500KVA

Figure 6 Electricity Distribution Transformers

The sound frequencies produced due to loading in transformer is twice the input frequencies $(2 \times 50 \mathrm{~Hz})$. The cut-off frequencies constants $a$ and $b$ for the LPF and BPF were selected as shown in the table 2 .

Table 2: Cut-off Frequencies Constant of Filters

\begin{tabular}{|l|c|c|l|}
\hline Filter & $\boldsymbol{a}$ & $\boldsymbol{b}$ & Bank \\
\hline BPF & 0.3 & 0.5 & Pass Band $90-120 \mathrm{~Hz}$ \\
\hline LPF & & 0.04 & Pass Band $0-120 \mathrm{~Hz}$ \\
\hline
\end{tabular}

In figure 7 , discrete values of sampled signals and noise plotted again time in second(s), some gradual load fluctuations have been noticed while background noise remained relatively steady during day time but dropped little at night times in (a). Figure 7 (b) had witness more drastic fluctuations in load signal but steady noise levels.
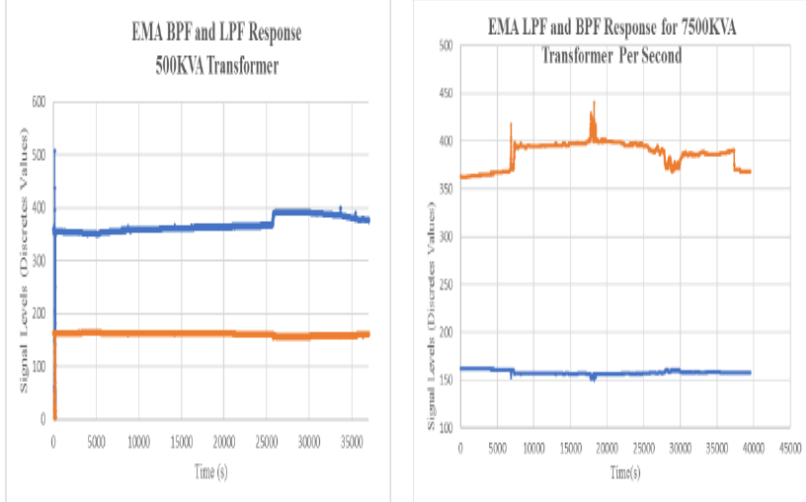

(a) $500 \mathrm{KVA}$
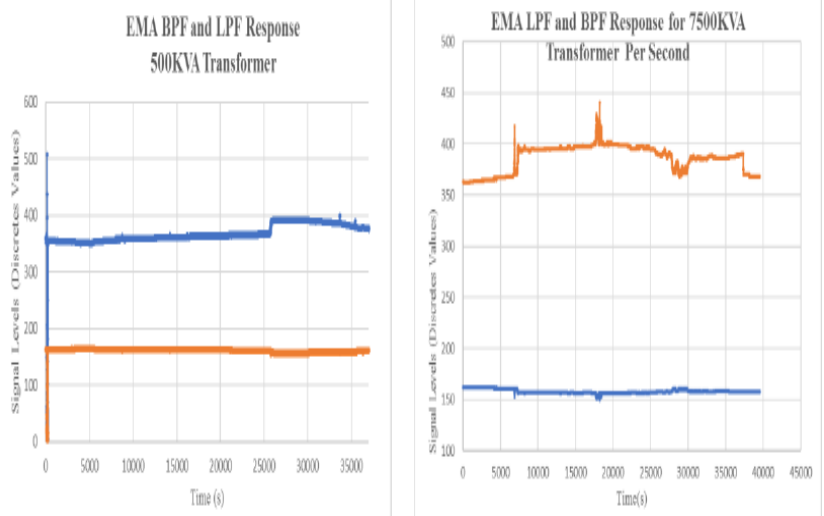

(b) $7500 \mathrm{KVA}$

Figure 7 Transformer Response to Load in seconds (s)
Figure 8 shows the responses of the two transformers per/hour. The results clearly indicate both transformers experienced sharp rise of loading between $3-4 \mathrm{pm}$. There were gradual fluctuations in loading between 4pm - 4am. By the time it was assumed normal activities have commenced for day, the graph behaviours indicate maximum load on the transformer between $7 \mathrm{am}$ and $10 \mathrm{am}$.
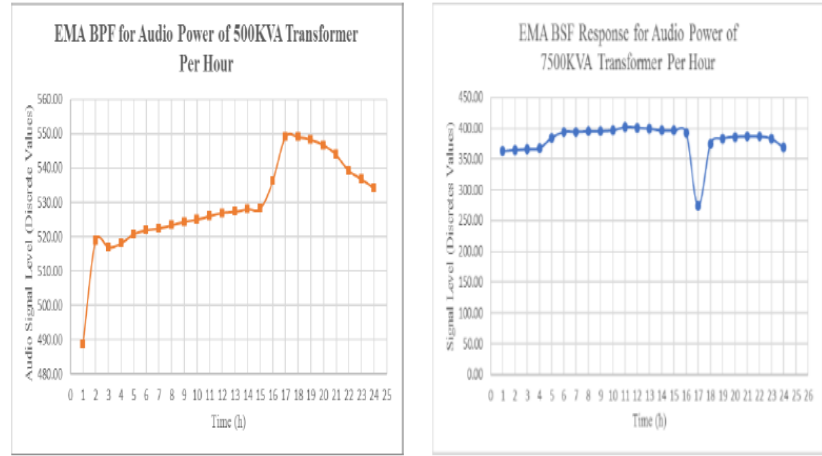

(a)
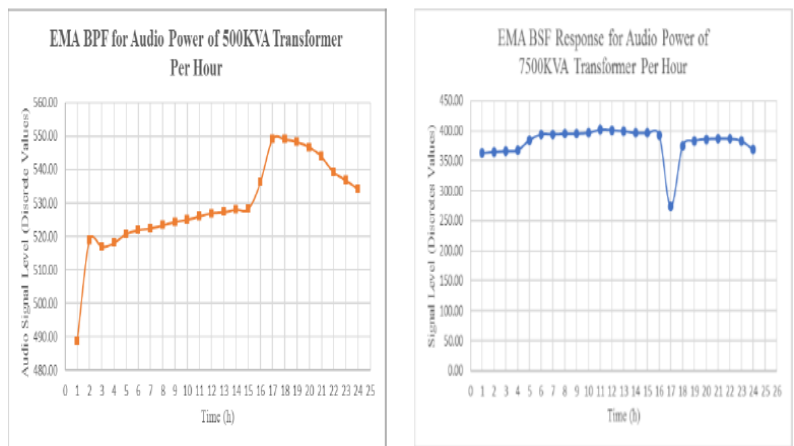

(b)

Figure 8 Load Respond of 7500KVA Transformer to Load Per Hour

\section{Signal dB level}

A cascaded two stages (pre-amplifier and power amplifier) was used to amplify the microphone signal. The overall gain $\mathrm{A}_{\mathrm{T}}$ was set to 250 .

$$
A_{T}=A_{\text {Pre-Amp }} * A_{\text {PowerAmp }}=250
$$

Where $\mathrm{A}_{\text {pre-amp }}$ and $\mathrm{A}_{\text {power Amp }}$ are the gain of the preamplifier and power amplifier.

The ADC was configured on 10bits resolution and its $\mathrm{V}_{\mathrm{REF}}$ is set to $5 \mathrm{~V}$.

Therefore, the actual microphone signal measured (sound signal level) in $\mathrm{dB}$ is given by;

$$
\begin{gathered}
d B=-20 \log \left(\frac{V_{O(\text { preamp })}}{V_{A D C V r e f}}\right) \\
V_{o(\text { preamp })}=\frac{D o}{A_{T} * D_{\max }}=\frac{D o}{51150} \\
d B=-20 \log \left(\frac{D_{O}}{255750}\right)
\end{gathered}
$$

$\mathrm{D}_{0}$ is the digital signal equivalent of the analogue input.

Figures 9 and Figure 10 shows the sound and noise $\mathrm{dB}$ levels over 24hours for the 500KVA and 7500KVA transformers respectively. A sharp rise in load lasted for about 3hours figure 9 (a).

Published By:

Blue Eyes Intelligence Engineering

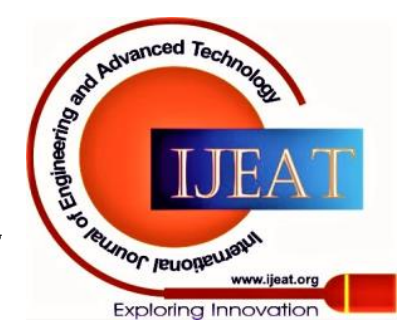




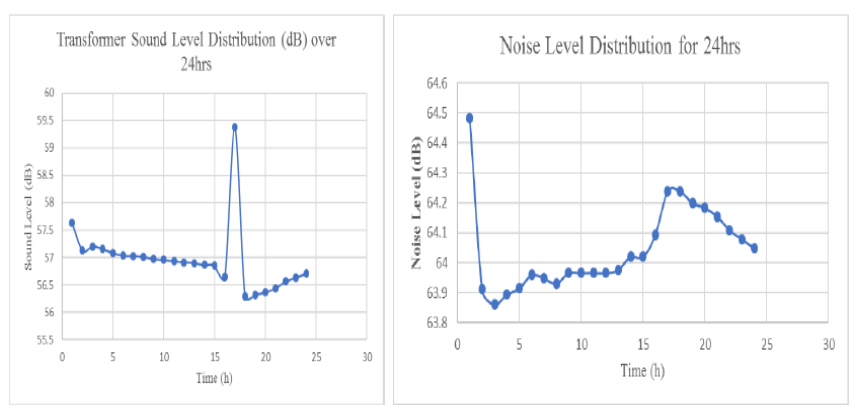

Load Sound Response

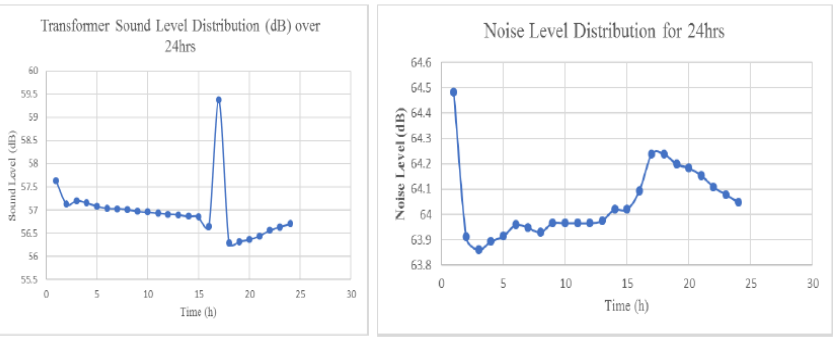

Background Noise

Figure 8: 500KVA Transformer Signals Level (dB) over 24hours

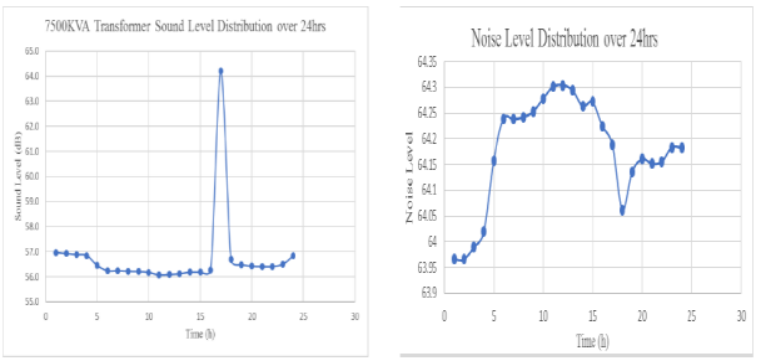

(a) Load Sound Response

(b) Background Noise

\section{Figure 9 7500KVA Transformer Sound Signal level dB or 24 hours}

Mapping of Sound (dB) range to Transformer ratings

Specifically, for the two transformers under consideration, and assuming perfect linearity between the transformer $\mathrm{dB}$ levels and the loads on the transformers. The $\mathrm{dB}$ value has been mapped into the power ratings to determine the load on the transformers.

Table 3: shows the sound level (dB) of 500KVA and 7500KVA Transformers [8] in conformity with NEMA standards 2006. The measured sound level $\mathrm{dB}$ in the two transformers and table 5 is their mapped loading levels and loading in percentage.

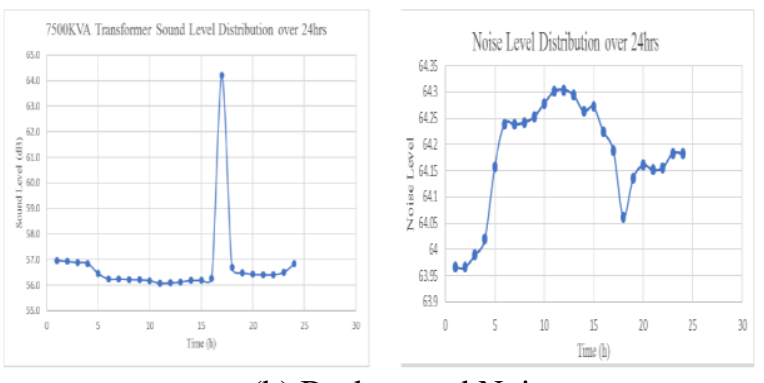

Table 3: Transformer sound(audio) level.

\begin{tabular}{|l|l|l|}
\hline \multicolumn{1}{|c|}{ Description } & 500KVA & 7500KVA \\
\hline $\begin{array}{l}\text { Sound level (dB) Maximum } \\
\text { (NEMA Standard 2006) }\end{array}$ & 56 & 72 \\
\hline Sound level (dB) Measured & 59.4 & 64.2 \\
\hline Load level (\%KVA) Max & 100.6 & 89.2 \\
\hline
\end{tabular}

\section{V.CONCLUSION}

In conclusion, loading limits monitoring in transformers in distribution network is essential. Adopting sound levelbased loading limits monitoring could improve device performance, service life and reduce cost of maintenance. The load fluctuation most times could result in transformers overload over a long period (hours). If the loading experience persists higher failure rate and subsequent declined in service life is inevitable. In this research we were able to use sound level-based monitoring to reveal loading pattern in 500KVA and 7500KVA transformers where an overload by factor of $0.6 \%$ was detected in 500KVA transformer. Further work is recommended, adding wireless radio such as GSM module to the embedded device (data logger board) will enable remote monitoring of performance, health, failure prediction. This will further ensure improved and steady supply of quality and useful electricity energy to users.

\section{REFERENCES}

1. S. G. Ramsis, G. M. Keith, Bernesjö and J. Anger, "Measuring No Load and Load noise of Power Transformers using the Sound Pressure and Sound Intensity Methods," ABB Power Transformers, St. Louis, MO, USA.

2. A. Petrovic, L. Ljubomir, K. Milan and L. Dusica, "Noise Measurements of the Power Transformers," 23rd and 4th International Conference University of NIS Faculty of Operational Safety, pp. 263267, 2012.

3. K. Daniel, G. Miroslav, Š. Milan, K. Matej and Z. Pawel, "Analysis of thermal processes in oil distribution transformer," PRZEGLĄD ELEKTROTECHNICZNY, pp. 79 -81, 2014.

4. International Electrotechnical Commission, "Loading guide for oilimmersed power transformers IEC 60076-7," International Electrotechnical Commission, 2005.

5. A. J. Moses, P. I. Anderson, T. Phophongviwat and S. Tabrizi, "Contribution of Magnetostriction to Transformer Noise," in Proceedings of the Universities Power Engineering Conference, 2010.

6. B. Rick, L. Vito, Emily, Saarela, G. Gerry and W. Gene, "Power Transformers, The quiet life," Transformers - T\&D Products Ltd., Ontario, 2017.

7. D. M.-C. Juan, F. N. Diego and F. E.-I. Diego, "Evaluation of the audible noise level on distribution transformers using the Sound Pressure Method," Revista Facultad de Ingeniería Vol. 26, pp. 71 -82, 2017.

8. Central Electricity Authority New Delhi India, "Guidelines for Specification of Energy Efficient Outdoor Type Three Phase and Single Phase Distribution Transformers," Ministry of Power India, New Delhi, 2008.

9. N. Nagaraju and M. Kiruthika, "FAULT SENSING IN A REMOTE TRANSFORMER USING GSM \& AUTOMATIC ON/OFF OF STREET LAMPS," International Journal of Advanced Research in Electrical, Electronics and Instrumentation Engineering, pp. 46204626, 2013.

10. T. A. Short, Electrical Power Distribution Handbook, Newyork: Taylor \& Francis Group, 2014.

11. S.-G. Katarzyna, "Guide for electrical design engineers," 12102017 [Online]. Available: www.leonardo-energy.org.

12. R. Godina, M. G. R. Eduardo, C. O. João, Matias and P. S. C. João, "Effect of Loads and Other Key Factors on Oil-Transformer Ageing: Sustainability Benefits and Challenges," Energies 2015, pp. 12147 12186, 2015.

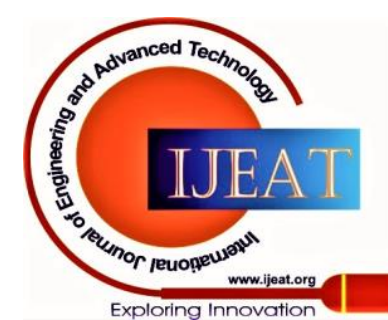




\section{Real-time Sound Level-Based Load Estimation in Distribution Transformer}

13. P. Gill, Electrical Power Equipment Maintenance and Testing, Second Edition, CRC Press, 2016.

\section{AUTHORS' PROFILE}

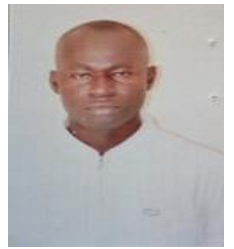

Patrick Ayuba Avong, is a lecturer and researcher in the department of Electrical and Electronic Engineering Technology, Federal Polytechnic Nasarawa, Nigeria. He obtained M.Sc. in Embedded Microelectronics and Wireless Systems from Coventry University UK in 2014 and B.Eng. Electrical/Computer Engineering from Federal University of Technology Minna Nigeria in 2006. His research focuses in areas of Embedded Systems design, Artificial Intelligence, Sensors technology and Electric Vehicle Technology (EVT). $\mathrm{He}$ is a registered member of Nigerian Society of Engineers (NSE).

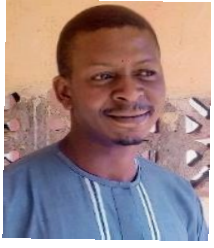

Usman Omeiza Ahmed, is working as a Lecturer, Department of Electrical and Electronics Engineering Technology, Federal Polytechnic Nasarawa, Nasarawa, Nigeria. A registered member of the Council for the Regulation of Engineering in Nigeria (COREN), in addition to holding a corporate membership of the Nigerian Society of Engineers (NSE). He is also pursuing specialization in Control.

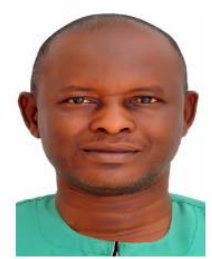

Bashayi Gaina James, is a principal lecturer in the department of Electrical/Electronic Engineering Technology, Federal Polytechnic Nasarawa, Nigeria. He holds a master degree (M.Eng) in Electrical Power System Engineering from Federal University of Agriculture, Makurdi in 2014 and HND/PGD in

Electrical Power Systems/Machines from Federal Polytechnic Bauchi/Ladoke Akintola University of Technology Ogbomoso in 2001/2005 respectively. His research area is in power system reliability, control, stability and instrumentation. He is a registered member of Nigeria Society of Engineers as well as Council for the Regulation of Engineers in Nigeria (NSE/COREN).

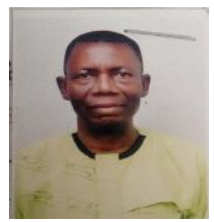

Caleb Akezi Amlabu, he is a Principal Lecturer in Department of Electrical/Electronic Engineering Technology, Federal Polytechnic Nasarawa, Nigeria. He attended L.E.A Primary School Ecewu, Kogi State between 1972-1978 and Technical College Ankpa 1978-1990. Caleb attended Kaduna Polytechnic between 1984 - 1990 where he obtained ND and HND certificates. He later proceeded to Federal University of Technology Minna between 1990 -2000 and Laduke Akintola University of Technology 2003 2005 where he obtained PGD computer science and Electrical Power System respectively all in Nigeria. He is currently holding M.Eng. in Power Systems Engineering from Federal University of Agriculture and a registered member of Council for Regulation for Engineering (COREN) and Nigerian Society for Engineers.

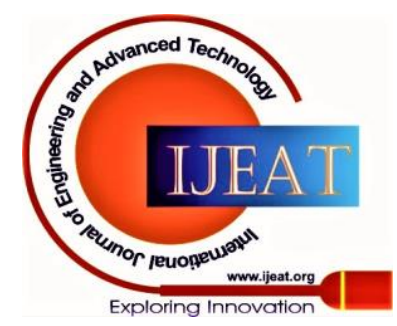

